\title{
Research on Standardized Evaluation of Administrative License
}

\author{
Xiaowen $\mathrm{Xu}$ \\ China National Institute of Standardization \\ Beijing, China
}

\begin{abstract}
Standardized evaluation of administrative license refers to the process of comprehensively measuring and evaluating the standardization degree and satisfaction degree of administrative license by using a series of evaluation variable data and using appropriate evaluation methods or models. On the basis of theoretical integration, field research and literature research, this project puts forward two main methods for standardized assessment of administrative license, hoping to provide specific, easy to understand and effective guidance for standardized assessment of administrative license.
\end{abstract}

Keywords-standardization; on-line government services platforms; administrative license

\section{INTRODUCTION}

The standardized evaluation of administrative license has not only policy guiding factors but also practical significance. Under the premise of continuous improvement, the administrative licensing procedures in China show a trend of standardization. However, in the process of the actual operation of the program, there are also cases of low standardization degree of administrative license and poor satisfaction degree of administrative license. This is due to the lack of legal norms, communication between multiple departments is not smooth, and job responsibilities are not clear and other practical factors. In order to build a lawbased, efficient and service-oriented government and to promote the standardization construction of administrative licensing, the standardization evaluation of administrative licensing should be studied and promoted.

\section{THE BASIC CONCEPT OF AdMINISTRATIVE LICENSE STANDARDIZED EVALUATION}

\section{A. The Basic Concept of Administrative License}

The concept of administrative license is the premise of studying the conditions, basis, term and decision of administrative license. The concept of administrative license is different in the theoretical circle of our country, which can be roughly divided into two meanings: first, it is considered that administrative license is in accordance with the provisions of laws, regulations and rules, and the administrative subject, according to the application of the applicant, grants him the capacity to engage in specific activities or confirms his capacity to have a certain right. This view believes that administrative licensing is the implementation of administrative management, is a way of administrative management. Second, experts believe that administrative license refers to the public applying to the administrative subject for the qualification to engage in certain activities, and the administrative subject granting the qualification to engage in certain activities in accordance with laws and regulations. In this view, it is an act that administrative power endows citizens with rights and endows citizens with the qualification to engage in certain activities. The author thinks that the concept of administrative license is: the administrative organ permits or revokes, changes or changes the powers and functions of citizens, legal persons or other organizations in accordance with laws and regulations, which are both the implementation of management and the entrusting of rights.

\section{B. The Basic Concepts of Standard, Standardization and Standardized Assessment}

Standards and standardization is the basis of the theory of standardization, the concept of core and the starting point, is the common object standardization, standardization activities and the essential attribute of abstract, is different from other standardization activities of key production activities, social activities, determines the object and scope of the standardization activities, purpose, principles, methods and so on many theoretical problems. Therefore, the definition of standards and standardization is the important basis of this study. According to the definition of ISO/IEC Guide2:1996, China's national standard GB/ t20000.1-2002 puts forward that the standard is "a normative document jointly used and reused by consensus and approved by recognized institutions in order to obtain the best order within a certain range". Standardization is "the activity of establishing common usage and reuse clauses for real or potential problems in order to obtain the best order within a certain range." Based on the concept of standards and standardization, standardized assessment is a process that comprehensively measures and evaluates the degree of standardization construction and satisfaction of standardization subject by using a series of assessment variable data and appropriate assessment methods or models.

Standardized evaluation of administrative license is a process to comprehensively measure and evaluate the standardization degree and satisfaction degree of administrative license by using a series of evaluation variable data and appropriate evaluation methods or models. 


\section{RESEARCH BACKGROUND AND SIGNIFICANCE OF ADMINISTRATIVE LICENSING STANDARDIZED ASSESSMENT}

\section{A. The Background of Administrative License Standardization Evaluation}

On February 04, 2015, the notice of the state council on standardizing the administrative examination and approval of state council departments to improve the work of administrative examination and approval [State Council (2015 No.6)] requires: "explore the implementation of the performance management of administrative examination and approval, improve the relevant assessment system of standardized examination and approval behavior, and conduct regular training, assessment, inspection and evaluation of the personnel in charge." The national standardization system construction and development plan (2016-2020) clearly proposes to "strengthen the standardization of government management and improve administrative efficiency", and lists the key points of government management standardization during the 13th five-year plan period.

In practice, the standardization construction in the field of administrative licensing in China is also advancing steadily. In July 2016, the state council review and reform office and the national standards commission jointly issued the notice on promoting the standardization of administrative licensing [Review and Reform (2016 No. 4)], officially launched the guidelines on the standardization of administrative licensing (2016 edition) (hereinafter referred to as the "guidelines"), which marks the initial entry of China's administrative licensing standardization threshold. However, due to the legal basis, staff quality, departmental interest barriers and other reasons, the standardized procedures of administrative licensing are uneven, and the satisfaction of administrative counterparts is not high enough, so it is necessary to strengthen the assessment of administrative licensing work, among which the standardized assessment of administrative licensing is an important part of the assessment.

\section{B. The Significance of Standardized Evaluation of Administrative License}

1) Regulating government behavior and building a law-based government: Comprehensively advancing the rule of law is the basic strategy for the party to lead the people in governing the country. "Government, the rule of law in the context of the rule of law is to point to in a country or place, law independent of government, at the same time to time is subject to laws and the legal construction of state" the American scholar Unger (Roberto $\mathrm{m}$. Unger) think, one aspect is the legal standard sex characteristics, it is equal to the rights and obligations, is to use the view of society and the universe as order to realize the behavior rule, established and the tendency of van. In terms of specific practice, "law is an important basis for the standardization of government behavior. However, due to its professionalism, generality and principle, it is weak in guidance and operation in practice. Standardization bears the responsibility of refining, operationalizing and popularizing the law, and is the real implementation of the concept and provisions of the law." That is to say, administrative licensing standardization assessment comprehensively measures and evaluates the standardization construction degree and satisfaction degree of standardization subjects, promotes the further improvement of standardization work, promotes the further standardization and standardization of government services, and contributes to the construction of a law-based government.

2) Streamlining administration and delegating power to build an efficient government: Decentralization is the necessary condition of building the efficiency of government and the standardization of administrative licensing and its evaluation is one of the important gripper and decentralization, push forward the standardization of administrative licensing, is to ensure that the administrative approval rights to put down, pick up the important measures, and standardized assessment of administrative license is based on data variables, using the appropriate methods or models, to standardize the standardization of subject construction and satisfaction degree of comprehensive measurement and evaluation of important tool, it provides analysis of the administrative licensing standardization construction level with specific reference, thus strengthening the administrative licensing standardized assessment can reverse pushing forward the construction of the standardization of administrative license so as to promote and decentralization, Improve government efficiency and build an efficient government.

3) Upgrading the experience of administrative counterparts and building a service-oriented government: From the macro level, the standardization of administrative license is a powerful means to regulate the government behavior, promote the simplification of administration and delegation of power, and balance the efficiency and fairness. To be specific, with the continuous development of administrative license standardization, it has gradually expanded from the basic fairness and efficiency orientation to a more specific level, and gradually optimized the site construction, personnel management and other details to fully improve the administrative license counterparts' work experience.

4) Scientific and comprehensive evaluation promotes the standardization of administrative licensing construction: Administrative licensing standardized evaluation is an important link in the construction of administrative licensing standardization. On the one hand, it is helpful to objectively evaluate the current standardization construction of administrative license. On the other hand, it is helpful to guide the standardization construction of administrative license correctly. It is of positive strategic significance to solve the problem of uneven standardization degree of 
administrative license and promote the standardization construction of administrative license comprehensively.

\section{Standardized Evaluation Method OF ADMINISTRATIVE LICENSE}

Administrative license standardized evaluation can be divided into basic general administrative license standardized evaluation and online administrative license standardized evaluation.

\section{A. Standardized Assessment of Basic General \\ Administrative License}

The standardized assessment of basic general administrative licensing includes administrative licensing matters management, administrative licensing process management, administrative licensing services, construction and management of places where administrative licensing is accepted, and administrative licensing supervision, inspection and evaluation. After sorting and summarizing, it is divided into regular evaluation index and bonus evaluation index.

1) Regular measures: According to the provisions of the guidelines, the indicators involve five aspects, namely, administrative licensing matters management, administrative licensing process management, administrative licensing services, construction and management of places where administrative licensing is accepted, and administrative licensing supervision, inspection and evaluation.

a) Administrative licensing matters management indicators: In terms of item management, the standardization degree of administrative license item management is measured mainly by measuring indexes such as list, name, basis, object and coding of administrative license item. The core content is to promote list management, dynamic management and coding management of administrative license item.

b) Administrative licensing process management indicators: In terms of process management, it mainly measures the important indicators of administrative license implementing organs in the process of accepting, reviewing and deciding administrative licenses, measures the implementation of the guidelines by administrative license implementing organs, and measures the standardization degree of administrative license process.

c) Administrative licensing service index: In terms of service, it mainly measures such indicators as the standardization of administrative license service system and the compilation of administrative license service guide, and measures the service awareness, service ability, service measures and service standardization of administrative license implementing agencies.

d) Construction and management index of administrative license accepting place: In terms of the construction and management of acceptance sites, it mainly measures the establishment and construction of acceptance sites, management of acceptance sites and other indicators to measure the standardization of the construction and management of administrative license acceptance sites.

e) Administrative licensing supervision, inspection and evaluation indicators: In terms of supervision, inspection and evaluation, it mainly measures the basic situation of administrative license implementing organs' supervision, inspection and evaluation of their own administrative license by measuring such indicators as supervision, inspection and evaluation of administrative license.

2) Assessment indicators for additional points: It can be formulated according to the current policy guidance of the competent department of the state council. For example, according to the policy requirements of the state council on administrative examination and approval in recent 2 years, and it can be refined into standardized indicators.

- The completion of key tasks of administrative licensing standardization;

- The successful experience and practices adopted by departments or regions in promoting work.

In general, the setting of bonus points should be considered in combination with the actual situation.

\section{B. Online Administrative Licensing Standardized Assessment}

1) The particularity of online administrative license standardization determines that its evaluation content is more complex than that of basic general administrative license standardization. It is necessary to standardize its content by referring to the standardized evaluation content of basic general administrative license and combining with its own characteristics. Now take the department evaluation as an example to illustrate. According to the actual operation of online administrative license, the department evaluation includes two kinds: basic evaluation index and innovation and convenience measure index. Among them, the basic evaluation indexes of online administrative license include five aspects, such as online platform function, compliance of administrative license service, satisfaction of administrative counterparts, construction of supervision and assessment system, and violations.

2) Basic assessment indexes of online administrative license: According to the actual operation of online administrative license, the evaluation content of the department includes six aspects: online platform function, compliance of administrative license service, satisfaction of administrative counterparts, construction of supervision and assessment system, innovation and measures for convenience of people, and violations.

3) Basic assessment index of online administrative license

a) Online platform function indicators: In terms of the functions of the office platform, it measures the efficiency, 
effectiveness and timeliness of the platform mainly by measuring its consulting, handling and docking level. The core content is to promote the establishment of a platform system with smooth information flow and timely and effective platform functions.

b) Compliance index of administrative licensing service: In administrative licensing service, regulatory compliance involves the system of administrative licensing behavior, documents, procedures, many Angle, from the perspective of more than a few set index, administrative licensing service level of compliance to specific quantitative, its core is to promote reasonable administrative licensing service documents, action compliance, solid foundation, open and high efficiency.

c) Administrative counterpart satisfaction index: In terms of the satisfaction of administrative counterparts, it mainly focuses on collecting and analyzing the satisfaction of administrative counterparts in time and improving and improving the satisfaction of administrative counterparts.

d) To supervise the construction of the appraisal system: In terms of the construction of the supervision and assessment system, the evaluation is conducted from the three levels of supervision, complaint and appeal feedback to measure the perfection of the supervision mechanism, information channel and complaint improvement within the supervision and assessment system.

e) Index of violations: In terms of index of violations, it mainly measures the degree of violations of administrative license implementing organs by measuring the acceptance, handling and feedback process of administrative license matters. Its core content is to force the standardization construction of administrative license by quantifying the degree of violations.

f) Index of innovation and convenience measures: In terms of innovation and convenience measures, it mainly measures the simplification and convenience of administrative services provided by administrative license implementing organs by evaluating the online service materials, procedures and other indicators.

\section{CONCLUSION}

Based on the theory of administrative license standardized evaluation, this paper summarizes the main methods and contents of administrative license standardized evaluation in detail. Combined with the actual situation of the continuous promotion of "Internet + government affairs service" in China, this paper gives full consideration to the particularity of online administrative license, especially the lack of theoretical and practical guidance in the new field of "online administrative license", although some provinces have taken the lead. Therefore, this paper faces the online and offline administrative licensing approaches, faces up to the existing problems, conducts an in-depth study on the corresponding two standardized assessment methods of administrative licensing, and makes some achievements, so as to provide reference for similar studies.

\section{ACKNOWLEDGEMENT}

This article in this phase is part of a state-funded key research program, namely, Research on Standardization and Evaluation of Administrative License (Project No.:572017Z5592-02)

\section{REFERENCES}

[1] Ying songnian, administrative law of contemporary China (part I) [M]; Beijing: China founder publishing house; In 2005.

[2] Li chuntian. Introduction to standardization (6th edition) [M]. Beijing: China renmin university press, 2014

[3] Tian yingbin, GUI yihua: an analysis of the value orientation and index system of government by law. Journal of hubei university of education, no.3, 2006, page 36 .

[4] Unger, law in modern society, translated by wu yuzhang and zhou hanhua, China university of political science and law press, 1994, p. 43.

[5] Huang hengxue, zhang yong, Ed. Research on the standardization of basic government public service. People's publishing house 2011 edition; On page 109

[6] Lu yuexin: theory and practice of standardized management of administrative license -- a case study of administrative examination and approval reform of afforestation and forestry in Shanghai, China university of political science and law press, 2016, page 2.

[7] Long haibo, wang xiongjun. Dividends and performance evaluation of administrative approval reform: 2013-2015. China development press, 2016 edition, page 98

[8] Irene and wang gang, exploration on the reform of administrative examination and approval system, people's publishing house 2015 edition, page 395 